\title{
O bisneto do comendador: herança cultural e formação autodidata em uma trajetória no século XX
}

\author{
Lisiane Sias Manke* \\ Ana Maria de Oliveira Galvão*
}

\section{RESUMO}

O artigo tem por objetivo compreender os processos de aproximação das culturas do escrito por um indivíduo autodidata, e suas práticas atuais de leitura e escrita. Trata-se de um estudo de caso emblemático, que possibilita problematizar questôes que estáo na base dos estudos sobre história e sociologia da leitura, sendo três as dimensôes privilegiadas na análise: a) o pertencimento social e a não linearidade geracional no que se refere à participação na cultura escrita; b) as práticas autodidatas desenvolvidas para o domínio do sistema escrito; e c) o trânsito entre o oral, o escrito e as sociabilidades na apropriaçáo das leituras. As práticas intelectuais desenvolvidas por esse indivíduo reforçam a necessidade de náo considerarmos oralidade e escrita como polos dicotômicos, pois mostram, especialmente, que oral e escrito agem simultaneamente na formação das disposiçóes sociais, resultando em usos específicos da escrita e da leitura.

Palavras-chave: cultura escrita; história da leitura; oralidade; autodidatismo.

\section{ABSTRACT}

The article aims to understand the processes of approximation of cultures within the writings of a self-taught individual, and his current practices of reading and writing. It is an emblematic case study, which makes it possible to problematize questions underlying the study of the history and sociology of reading. In the analysis, three dimensions were favored: a) social belonging and the generational non-linearity regarding the participation in written culture; $b$ ) the self-taught practices developed in order to master the written system; and c) the transition among what is oral, what is written, and the sociabilities in the appropriation of readings. The intellectual practices developed by this individual reinforce the need not to consider orality and writings as dichotomous poles, because these two dimensions of language act simultaneously in the formation of social disposition, resulting in specific uses of writing and reading. Keywords: written culture; history of reading; oral language; autodidactism.

DOI: http://dx.doi.org/10.1590/2237-101X01903705

Artigo recebido em 12 de dezembro de 2016 e aprovado para a publicação em 12 de setembro de 2017.

* Professora da Universidade Federal de Pelotas. E-mail: lisianemanke@yahoo.com.br.

** Professora da Universidade Federal de Minas Gerais. E-mail: anamgalvao@uol.com.br. 


\section{O BISNETO DO COMENDADOR: HERANÇA CULTURAL \\ E FORMAÇÃ̃O AUTODIDATA EM UMA TRAJETÓRIA NO SÉCULO XX \\ Lisiane Sias Manke | Ana Maria de Oliveira Galvão}

\section{RESUMEN}

Este artículo tiene por objetivo comprender los procesos de aproximación de las culturas de lo escrito por un individuo autodidacta, y sus prácticas actuales de la lectura y escritura. Se trata de un estudio de caso emblemático, que posibilita problematizar cuestiones que están en la base de los estudios sobre historia y sociología de la lectura, siendo tres las dimensiones privilegiadas en el análisis: a) la pertenencia social y la no linealidad generacional en lo que se refiere a la participación en la cultura escrita; b) las prácticas autodidactas desarrolladas para el dominio del sistema escrito; y c) el cambio entre lo oral, lo escrito y las sociabilidades en la apropiación de las lecturas. Las prácticas intelectuales desarrolladas por ese individuo refuerzan la necesidad de no considerar la oralidad y la escritura como polos dicotómicos, pues ellas muestran, especialmente, que lo oral y lo escrito actúan simultáneamente en la formación de las disposiciones sociales, resultando en usos específicos de la escritura y la lectura.

Palabras claves: cultura escrita; historia de la lectura; oralidad; autodidactismo.

Os detalhes de uma trajetória de vida possibilitam a compreensão da dinâmica social em sua complexidade. Permitem, ainda, compreender o modo pelo qual o peso das circunstâncias direciona o curso da vida para direçôes muitas vezes improváveis, frente ao mais provável. O social analisado em pequena escala apresenta outras lentes para fenômenos globais, normalmente abordados a partir de estruturas planas. ${ }^{1} \mathrm{O}$ processo de organização e democratização do sistema escolar, a difusão do impresso nos diferentes grupos sociais, as taxas de alfabetização e analfabetismo, entre outros fenômenos, podem ser analisados de modo completamente distinto se forem investigados em escala individual, a partir da trajetória daqueles que vivenciaram esses processos e da particularidade que envolve os diversos percursos sociais. Assim, ao reconstruir a experiência de atores singulares vislumbramos os múltiplos contextos que lhe dâo forma e sentido, possibilitando-nos perceber o entrecruzamento das lógicas sociais. Cada indivíduo representa as "dobras do social", ou seja, a realidade social na sua forma incorporada. Neste sentido, "o ator individual é o produto de múltiplas operaçóes de dobramentos (ou de interiorizaçáo) e se caracteriza, portanto, pela multiplicidade e pela complexidade dos processos sociais (...) que interiorizou". ${ }^{2}$

Nesse artigo, objetivamos compreender os processos de aproximação das culturas do escrito por um indivíduo autodidata, ao longo de sua trajetória de vida, e suas práticas atuais de leitura e escrita. A partir da análise das vivências relatadas e observadas, de documentos

\footnotetext{
${ }^{1}$ Para uma discussão sobre micro-história e jogos de escalas, ver, ao menos, LEVI, Giovanni. Sobre a microhistória. In: BURKE, Peter. A escrita da história: novas perspectivas. São Paulo: Unesp, 1992; REVEL, Jacques (Org.). Jogos de escalas. Rio de Janeiro: Fundação Getulio Vargas, 1998.

${ }^{2}$ LAHIRE, Bernard. Homem plural: os determinantes da ação. Petrópolis, RJ: Vozes, 2002, p. 198.
} 


\section{O BISNETO DO COMENDADOR: HERANÇA CULTURAL \\ E FORMAÇÃ̃O AUTODIDATA EM UMA TRAJETÓRIA NO SÉCULO XX}

Lisiane Sias Manke | Ana Maria de Oliveira Galvão

pessoais e manuscritos produzidos por esse indivíduo, será possível problematizar as circunstâncias e as instâncias sociais que possibilitaram sua participação em práticas que envolvem a palavra escrita, assim como evidenciar as possíveis marcas da cultura oral na relação que estabeleceu, ao longo da vida, com a leitura e com a escrita. Assim, o artigo se insere em um conjunto mais amplo de preocupaçóes que problematizam como a história da cultura escrita tem sido construída, particularmente em países de disseminação tardia da imprensa e da escolarização, como é o caso do Brasil.

Pesquisas realizadas em diversos países, ${ }^{3}$ vinculadas sobretudo a pressupostos da história cultural, que envolvem o estudo de práticas culturais de indivíduos de meios populares, trouxeram significativa contribuição para a história da leitura e dos leitores, especialmente em relação ao contexto europeu, ao investigar meios e modos de ler ao longo do tempo. Contudo, ainda é um desafio desenvolver uma "história da reação do leitor (...), pois os documentos raramente mostram os leitores em atividade, modelando o sentido a partir dos textos". “ A relação que esses indivíduos estabelecem com a cultura escrita, especialmente quando estão imersos em práticas socioculturais vinculadas à oralidade, ainda é um enigma que vem sendo desvendado com o aprofundamento das investigaçóes realizadas no campo. No Brasil, a coletânea de estudos monográficos publicada por Ana Maria de Oliveira Galvão e colaboradores ${ }^{5}$ mostra que modos de inserção não escolares, o manuscrito e a oralidade são dimensões constitutivas da cultura escrita no país, contrariando a ideia difundida na historiografia tradicional de que a escola é a única ou principal via de entrada na cultura escrita. Esse conjunto de estudos evidencia, assim, que a análise de trajetórias individuais possibilita compreender, de modo mais específico, os diferentes mecanismos utilizados e as diversas instâncias sociais que constituem a experiência de indivíduos comuns, tradicionalmente vinculados à oralidade, com as práticas relacionadas à cultura escrita.

$\mathrm{O}$ ator pesquisado neste artigo chama-se Ismael, nasceu no ano de 1921, no município de Canguçu, ${ }^{6}$ Rio Grande do Sul, e era filho de produtores rurais de origem portuguesa. O local em que nasceu foi também o palco de sua trajetória de vida profissional, onde desenvolveu atividade como pecuarista e agricultor, em uma propriedade rural de aproximadamente 100 hectares, até o ano de 1995, quando, já aposentado, passou a residir na sede urbana do

\footnotetext{
${ }^{3}$ Para citar alguns exemplos: DARNTON, Robert. A leitura rousseauista e um leitor "comum" do século XVIII. In: CHARTIER, Roger (Org.). Práticas de leitura. São Paulo: Estação Liberdade, 2001; HÉBRARD, Jean. O autodidatismo exemplar. Como Valentin Jamerey-Duval aprendeu a ler? In: CHARTIER, Roger (Org.). Práticas de leitura. São Paulo: Estação Liberdade, 2001; GINZBURG, Carlo. O queijo e os vermes: o cotidiano e as ideias de um moleiro perseguido pela Inquisição. São Paulo: Companhia das Letras, 1987.

${ }^{4}$ DARNTON, Robert. O beijo de Lamourette: mídia, cultura e revolução. São Paulo: Companhia das Letras, 1995 , p. 148.

${ }^{5}$ GALVÃO, Ana Maria de Oliveira et al. História da cultura escrita: séculos XIX e XX. Belo Horizonte: Autêntica, 2007.

${ }^{6}$ A localidade rural em que Ismael nasceu pertencia, na época, ao município de Canguçu. Em 1959, passou a compor o território do município de Pedro Osório. Em 1995, parte do território de Pedro Osório emancipouse, dando origem ao município de Cerrito.
} 


\section{O BISNETO DO COMENDADOR: HERANÇA CULTURAL \\ E FORMAÇÃ̃O AUTODIDATA EM UMA TRAJETÓRIA NO SÉCULO XX}

Lisiane Sias Manke | Ana Maria de Oliveira Galvão

município de Cerrito. Ismael não frequentou a escola, em virtude da inexistência dessa instituição na região em que morava. ${ }^{7}$ Foi alfabetizado por uma professora leiga, que em 1930 morou na casa de seus pais, com o objetivo de alfabetizar as crianças da região. A primeira e única vez que Ismael se afastou por algum tempo da localidade em que nasceu foi em 1945, durante a Segunda Guerra Mundial, quando tinha 23 anos, por convocação das Forças Armadas do Brasil, tendo sido direcionado ao quartel de Quaraí, também no Rio Grande do Sul. Durante os onze meses de serviço militar, Ismael vivenciou um período de grande desafio: a distância e a ausência de comunicação com a família, as condiçóes de vida no quartel e a tensão decorrente do estado de guerra. Essas vivências marcaram fortemente sua trajetória. Nesse período, estabeleceu uma relação de maior proximidade com o escrito, pois essa dimensão da linguagem passou a ter sentido prático nas relaçóes sociais que mantinha no cotidiano do quartel.

Ao retornar para casa, Ismael casou-se e continuou morando na propriedade que herdou de seu pai, onde constituiu família, composta por quatro filhos. Atualmente, estando aposentado e morando sozinho, desde o falecimento de sua esposa, vive cercado por livros que lhe foram presenteados, por textos fotocopiados de livros emprestados, por resumos que escreve e por listas que organiza. A leitura e a escrita ocupam seu tempo, seus pensamentos e lhe oferecem "conteúdo" para falar sobre o passado e o presente. Como veremos ao longo do artigo, trata-se de um caso ${ }^{8}$ emblemático para pensarmos questóes que estão na base de muitos estudos sobre história e sociologia da leitura: a não linearidade observada nos processos de aproximação da cultura escrita entre diferentes geraçôes de uma mesma família; as singularidades das formas de apropriação dos textos escritos; a indissociabilidade entre as dimensôes oral e escrita da linguagem; os lugares sociais e simbólicos ocupados pelo escrito ao longo do tempo; o papel dos textos didáticos em comunidades de circulação escassa da palavra escrita; as relaçóes entre leitores pouco escolarizados e a dimensão ética da leitura; as complexas articulaçóes entre autodidatismo, escolaridade e leitura.

Por se referir a um período histórico recente, que ainda conta com o testemunho dos atores sociais, a contribuição da história oral ${ }^{9}$ se fez imprescindível na realização da pesquisa e tor-

\footnotetext{
${ }^{7}$ Estudos indicam que a rede escolar do município de Cerrito permaneceu, até a segunda metade do século XX, bastante restrita. (Cf. MADEIRA, Claudemir Pereira. Da multisseriação à nucleação: a escola municipal Alfredo Dias de Cerrito/RS — Décadas de 1980 a 1990. Dissertação (mestrado) - PPGE/FaE/UFPel, Pelotas, 2010. Outro dado que converge com os depoimentos está no Censo de 1920, que revelou que 53,8\% da população gaúcha era analfabeta neste período. (Cf. FERRARO, Alceu Ravanello; KREIDLOW, Daniel. Analfabetismo no Brasil: configuração e gênese das desigualdades regionais. Educação e Realidade, v. 29, n. 2, p. 179-200, 2004.)

${ }^{8}$ Para uma discussão teórico-metodológica sobre a potencialidade do estudo de casos, sobretudo na pesquisa histórica e sociológica, ver: PASSERON, Jean-Claude; REVEL, Jacques (Dir.). Penser par cas. Paris: Éditions de l'École des Hautes Études en Sciences Sociales, 2005.

${ }^{9}$ Para uma discussão sobre a metodologia da história oral, ver, entre outros: AMADO, Janaína, FERREIRA, Marieta (Org.). Usos e abusos da história oral. Rio de Janeiro: Editora da Fundação Getúlio Vargas, 1996. MEIHY, José Carlos Sebe; HOLANDA, Fabíola. História oral: como fazer, como pensar. São Paulo:
} 
nou-se o principal aporte metodológico para a produção de dados, por meio da realização de entrevistas em profundidade. Vários encontros foram realizados, resultando na produção de longos depoimentos, que objetivaram apreender a trajetória do indivíduo em diferentes perspectivas de sua vida. As sete entrevistas com Ismael foram realizadas entre 2008 e 2016: duas em 2008; uma em 2009; uma em 2010; uma em 2015; duas em 2016. As últimas três entrevistas foram realizadas especialmente para a elaboração deste artigo.

Além dos dados coletados por meio da história oral, o rol de fontes analisadas é composto também pelas escritas produzidas por Ismael (formulários, memórias de acontecimentos vivenciados, cópias de livros didáticos, organização de dados pesquisados); pelo acervo de livros que possui e por documentos pessoais, tais como inventário, certificado de reservista e fotografias. Tanto as fontes orais quanto as escritas apresentam limites, sendo relevante, quando possível, "trabalhar com os dois registros, sem que isso signifique que sejam complementares" ${ }^{10}$ ou seja, sem que haja superioridade de um tipo de fonte sobre outro.

\section{Pertencimento social e (não) herança cultural: o bisneto do comendador}

Ismael é descendente de uma família portuguesa que teria chegado ao sul do território brasileiro no século XVIII. "O pai da família Caldeira”, como se refere ao seu bisavô, o comendador Manuel Joaquim Caldeira, possuía embarcaçóes marítimas, e recebeu da coroa portuguesa uma grande quantidade de terras no Brasil, possivelmente pelo sistema de sesmarias. ${ }^{11}$ As esparsas lembranças de Ismael sobre as histórias contadas pelo pai são acrescidas por um documento que permite fazer algumas consideraçóes sobre a história de seus antepassados: trata-se de um inventário ${ }^{12}$ registrado na comarca de Piratini (RS), no ano de 1848, que apresenta a relação de bens avaliados e partilhados entre os filhos do comendador Caldeira e da viúva Dorothea, a inventariante. Eram onze os filhos do casal, seis homens e cinco mulheres, que herdaram bens móveis e imóveis. Entre os imóveis constam três propriedades rurais que somavam 15.750 braças $^{13}$ de terra, e uma casa na cidade de Rio

Contexto, 2007. ALBERTI, Verena. Manual de história oral. Rio de Janeiro: Editora da Fundação Getulio Vargas, 2004. Ver, também, os diversos números do periódico História Oral, publicado pela Associação Brasileira de História Oral desde 1998.

${ }^{10}$ ALCÀZAR I GARRIDO, Joan del. As fontes orais na pesquisa histórica: uma contribuiçáo ao debate. Revista Brasileira de História, São Paulo, v. 13, n. 25/26, p. 40, set. 1992/ago. 1993.

${ }^{11}$ A concessão de terras no território do Rio Grande do Sul aos povoadores ocorreu no sistema de sesmarias (em média $3 \times 1$ légua) e datas (1/4 de légua quadrada). Cf. KÜHN, Fábio. Breve história do Rio Grande do Sul. 3. ed. Porto Alegre: Leitura XXI, 2002, p. 56.

${ }^{12} \mathrm{O}$ inventário foi localizado por um amigo da família e cedido a Ismael para que fizesse uma cópia, não se sabe ao certo onde está o documento original.

${ }^{13}$ Uma braça de sesmaria no Rio Grande do Sul, no período imperial, era o equivalente a 1,45 hectares de terra. (http://doc.brazilia.jor.br/HistDocs/Medidas-antigas-nao-decimais.shtml). 
Grande, ${ }^{14}$ que servia de residência para o casal. Entre os bens móveis foram inventariados quadros franceses, porcelanas, pratarias, camas, armários, mesas e cadeiras, escrivaninha, ferramentas de uso rural, animais, escravos e alguns livros, assim descritos:

Uma porção de livros em mau uso — seis mil réis;

Uma obra completa em mau uso de medicina — vinte mil réis;

Uma obra completa em bom uso de medicina, digo, de Racine — oito mil réis;

Dois dicionários de Moraes — seis mil réis;

Uma obra completa [ilegível] filosófica - vinte e quatro mil réis. ${ }^{15}$

Para que se tenha uma ideia do valor das obras inventariadas, comparamo-lo com o valor de bens móveis e imóveis mencionados no inventário: enquanto uma braça de terra valia 2.500 réis, uma escrivaninha foi avaliada em 40 mil réis, uma cama de jacarandá em 20 mil réis e os livros somavam a importância de 64 mil réis. Diante do montante de bens inventariados, os livros não representavam um patrimônio substancial, contudo, possuíam valor financeiro expressivo. Os dados não permitem uma análise mais profunda do conjunto de livros listados, não sendo possível fazer o levantamento quantitativo das obras, ou mesmo bibliográfico. No entanto, os termos que constam indicam para uma coleção completa de medicina, uma coleção de filosofia, uma obra completa de Racine e dois dicionários de Moraes. A referência a Racine indica tratar-se de obras de Jean Baptiste Racine, escritor francês do século XVII, considerado o maior dramaturgo clássico da França. No caso dos dicionários, a referência, certamente, é à obra de António Moraes Silva, que, em 1789, publicou o seu Diccionario da Lingua Portugueza, em Lisboa. Considerada uma obra quase perfeita para época, "o nome Moraes é hoje sinônimo de dicionário e autoriza sete edições posteriores às três primeiras que foram da lavra do brasileiro: 1789, 1813 e 1823 ” ${ }^{16}$

A partir do que é possível indicar com a análise desse documento, algumas questôes surgem: por quem eram usados esses livros em uma família de onze filhos? As obras teriam sido adquiridas para a instrução dos descendentes ou pertenceriam à biblioteca particular do comendador Caldeira? Para que eram utilizadas obras técnicas de medicina, ou mesmo aquelas de conteúdo filosófico? Que relação de proximidade com a cultura escrita esses livros podem indicar? Não se sabe que tipo de leitores/escritores eram os patriarcas da família ou mesmo se haviam frequentado alguma instituição escolar. Contudo, a presença de livros nesse inventário é um indício significativo da presença da cultura escrita entre os ancestrais

\footnotetext{
${ }^{14} \mathrm{Na}$ povoação de Rio Grande, criada em 1737, se estabeleceram os primeiros povoadores, que garantiram a posse portuguesa do continente por meio de uma política de enraizamento social e econômico. Cf. KÜHN, Fábio. Breve história do Rio Grande do Sul, op. cit., p. 54/55.

${ }^{15}$ Conforme descrição presente no inventário da família Caldeira, registrado na comarca de Piratini/RS, em 1848. ${ }^{16}$ MURAKAWA, Clotilde de Almeida Azevedo. Léxico e gramática no Diccionario da Lingua Portugueza (1813) de António De Morais Silva. São Paulo: Alfa, 2006, p. 65.
} 
de Ismael. Outros indicativos, na mesma direção, advêm da atuação social expressiva dos filhos do comendador Caldeira e de Dorothea Caldeira, ${ }^{17}$ que, durante a segunda metade do século XIX, protagonizaram alguns acontecimentos históricos no Rio Grande do Sul os quais exigiam um domínio mínimo da leitura e da escrita.

Nesse sentido, foi possível constatar que o avô de Ismael, Antonio Joaquim Caldeira — filho do comendador Caldeira — , teria sido eleito vereador da primeira câmara de vereadores do município de Canguçu, em 1857, ${ }^{18}$ participado da criação do Clube Abolicionista de Cerrito Velho em 1884 e atuado como cirurgião-mor durante a Guerra do Paraguai (1864-1870). ${ }^{19}$ Esses fatos foram registrados em textos históricos, exibidos por Ismael como "comprovantes" do que era narrado. Segundo ele, seu pai pouco lhe falou sobre as atividades sociais desenvolvidas por seu avô, a exemplo da função de cirurgião-mor, fato que desconhecia até encontrar essa informação em um livro que lhe fora emprestado. Ismael supóe que o avô tivesse formação em medicina, tendo estudado na Europa, visto que seu bisavô tinha embarcaçóes marítimas, o que facilitaria o deslocamento e o contato com o velho mundo.

Também acredita que seu tio-avô teria estudado em Portugal, pela relação de proximidade que tinha com a cultura escrita, uma vez que registros históricos indicam que o tenente Manoel Alves da Silva Caldeira (irmão do avô de Ismael) teria atuado como porta-estandarte do $1^{\circ}$ Corpo de Lanceiros Negros ${ }^{20}$ do exército da República Rio-grandense, durante a Revolução Farroupilha (1835-1845). Anos mais tarde, o tenente Manoel Caldeira escreveu 170 páginas sobre esse movimento, ${ }^{21}$ baseadas em suas memórias, que foram enviadas a historiadores, em forma de cartas, entre os anos de 1888 e 1898. Os depoimentos foram publicados na revista do Instituto Histórico e Geográfico do Rio Grande do Sul, em 1927, e no volume 5 dos Anais do Arquivo Histórico do Rio Grande do Sul, em 1981. Assim, o tenente Caldeira é considerado pela historiografia o maior cronista da Revolução Farroupilha, devido ao significativo número de registros que realizou a partir de sua atuação na revolução.

Os indícios localizados indicam, portanto, que os ancestrais de Ismael eram sujeitos de posses, proprietários de terras e escravos, com relativa proximidade com a cultura escrita.

\footnotetext{
${ }^{17}$ Em relação à família de Dorothea Caldeira, esposa do comendador, não foi possível obter qualquer informação.

${ }^{18}$ A atuação do avô de Ismael como vereador está registrada na Revista do $1^{\circ}$ centenário de Pelotas, obra de João Simôes Lopes Neto, na edição de oㅡㄴ 4, de janeiro de 1912, página 56.

${ }^{19}$ A participação de Antonio Joaquim Caldeira na criação do Clube Abolicionista, assim como na Guerra do Paraguai, está citada no livro intitulado Pedro Osório, sim senhor, de autoria de Pedro Caldas, publicado em 1990, páginas 42 e 49.

${ }^{20}$ Em 12 de setembro de 1836, foi constituído o 1 Corpo de Cavalaria de Lanceiros Negros, com mais de quatrocentos homens recrutados entre os negros campeiros e domadores para lutarem como soldados pela causa republicana. Cf. CARRION, Raul K. M. Os lanceiros negros na Guerra dos Farrapos. Ciências e Letras, Faculdade Porto-Alegrense de Educação, v. 37, p. 67-88, jan./jun. 2005.

${ }^{21}$ O jornal Diário Popular, em edição especial aos 150 anos de Revolução Farroupilha, no dia 20 de setembro de 1985, exibe uma matéria sobre o tenente Manoel Caldeira, denominada "De Pedro Osório, o maior Cronista Farrapo".
} 


\section{O BISNETO DO COMENDADOR: HERANÇA CULTURAL \\ E FORMAÇÁ̃O AUTODIDATA EM UMA TRAJETÓRIA NO SÉCULO XX}

Lisiane Sias Manke | Ana Maria de Oliveira Galvão

Seu avô parece ter tido atuação política definida — republicano abolicionista — , tendo participado no maior conflito armado internacional ocorrido na América do Sul no século XIX - a Guerra do Paraguai. Diante disso, cabe-nos inquirir: Que formação teria tido esse indivíduo? Onde e como aprendeu a ler e escrever? Teria cursado medicina na Europa? Seria ele o herdeiro dos livros de medicina que constam no testamento do comendador Caldeira? Haveria, entre seus pertences, livros, documentos, manuscritos que revelassem sua atuação na guerra do Paraguai? Que herança cultural transmitiu a seus quatro filhos - entre eles o pai de Ismael? Muitas dessas questóes ficarão sem resposta, pois se perderam no tempo e delas não restam nem mesmo memórias.

Contudo, os relatos de Ismael revelam que seu pai não era um herdeiro cultural, ${ }^{22}$ especialmente no que se refere às práticas relacionadas com a leitura e a escrita. Antonio Joaquim Caldeira Filho, nascido no final do período imperial, no ano de 1874, embora soubesse ler, não teria frequentado a escola, assim como seus irmãos. Como agropecuarista, não assumiu nenhum cargo de destaque social que o tivesse projetado além das fronteiras de sua propriedade rural. Tal condição é bastante lembrada por Ismael ao relatar as dificuldades vivenciadas pelo pai em um período histórico de grande instabilidade social no Rio Grande do Sul. Durante a República Velha (1893-1930), o estado foi palco de pelo menos duas revoluções, a Revolução Federalista e a Revolução de $1923,{ }^{23}$ resultado dos constantes embates entre federalistas e republicanos. Estas são as memórias mais expressivas de Ismael em relação ao seu pai:

Eu me criei vendo meu pai contar (...) pegavam os cavalos dos pobres colonos, ninguém era dono de nada (...), meu pai era dos federalistas quando Getúlio Vargas entrou, e estavam sofrendo muita perseguiçáo, então meu pai sempre contava que veio conhecer democracia quando Getúlio foi o governo, porque terminou com aquelas bagunça de revoluçóes. ${ }^{24}$

No entanto, não há evidências de maior participação de seu pai nas disputas partidárias, com atuação junto aos partidos políticos do período. Assim, enquanto as memórias de Ismael são povoadas pelas açóes política e social do bisavô e do avô, que os fizeram "entrar para a história oficial", lembra-se do pai como aquele que contava/narrava os acontecimentos vivenciados pela família.

\footnotetext{
${ }^{22}$ Referimo-nos a "herdeiro cultural" a partir do conceito desenvolvido por Bourdieu e Passeron, na obra: PASSERON, Jean-Claude; REVEL, Jacques (Dir.). Penser par cas, op. cit.. Mas, especialmente, considerando a revisão crítica realizada por De Singly e Lahire, nas obras: DE SINGLY, François. Savoir hériter: la transmission du goût de la lecture chez lês étudiants. In: FRAISSE, Emmanuel (Org.). Les étudiants et la lecture. Paris: PUF, 1993; DE SINGLY, François. L'appropriation de L'heritage culturel! Lien Social et Politiques, v. 35, p. 153-165, 1996; LAHIRE, Bernard. Homem plural: os determinantes da ação, op. cit.

${ }^{23}$ Sobre o período da República Velha (1889-1930) no Rio Grande do Sul, consultar: REKZIEGEL, Ana Luiza Setti; AXT, Gunter (Dir.). República Velha (1889-1930). Passo Fundo: Méritos, 2007.

${ }^{24}$ Conforme entrevista realizada em 2009.
} 


\section{O BISNETO DO COMENDADOR: HERANÇA CULTURAL \\ E FORMAÇÃ̃O AUTODIDATA EM UMA TRAJETÓRIA NO SÉCULO XX}

Lisiane Sias Manke | Ana Maria de Oliveira Galvão

Antonio Joaquim Caldeira Filho, viúvo e pai de quatro filhos, casou-se com Amélia Barbosa Caldeira, com quem constituiu o segundo casamento. O casal teve duas filhas e um filho: Ismael. Amélia também não teria frequentado a escola, mas sabia ler e escrever. Segundo relata Ismael, a família de sua mãe era composta por doze irmãos, todos alfabetizados, embora não escolarizados. O domínio da leitura e da escrita pela família Barbosa demonstra que, em um país de tardia ampliaçáo do sistema escolar, as tática ${ }^{25}$ utilizadas para a entrada no mundo escrito poderiam ser diversas, sendo o ensino doméstico, com alguém que dominasse o sistema escrito, uma alternativa para a aprendizagem das primeiras letras.

\section{Aprendizagens e usos do escrito: o autodidata Ismael}

Ismael, o bisneto do comendador, também não frequentou a escola. Aliás, não se sabe com precisão se alguém da linhagem familiar paterna tenha sido escolarizado, embora, como discutido, indícios apontem para o envolvimento da família com a cultura escrita. Vinculado a uma família rural, com pai e mãe não escolarizados, Ismael não se recorda de atividades realizadas pela família que envolvessem a prática da leitura e da escrita. $\mathrm{Na}$ localidade em que morava, Ismael relata não somente a ausência de escolas, mas também de igrejas, o que impedia práticas de socialização recorrentes no período, como a presença na missa semanal, atividade que poderia aproximar a família da cultura escrita. Não há também, em suas memórias, registro de momentos de leitura de textos bíblicos na casa paterna.

Porém, se não havia a prática de leitura e escrita sistematizada, ela não esteve totalmente ausente do contexto familiar. Em uma família sem histórico de escolarização, embora seja importante ressaltar que sem histórico de analfabetismo também, a crença na legitimidade cultural ${ }^{26}$ do escrito é perceptível. A família de Ismael abrigou durante um ano, em 1930, uma professora leiga, chamada Maria José Botelho Calderipe, solteira, de 67 anos, para alfabetizar os três filhos do casal e as crianças da vizinhança. Segundo seu relato, mesmo sem formação, ela "sabia ensinar, se não fosse ela eu não tinha aprendido nada, foi a única pessoa daquela época que sabia ensinar". ${ }^{27} \mathrm{O}$ pagamento pelo trabalho prestado era dividido entre os pais dos alunos. ${ }^{28}$

\footnotetext{
${ }^{25}$ Utilizamos, neste artigo, a palavra "táticas" no sentido que lhe confere DE CERTEAU, Michel. A invenção do cotidiano. Petrópolis, RJ: Vozes, 1994.

${ }^{26}$ Conforme os estudos da sociologia da crença e da dominaçáo cultural, "o fato de certos produtos culturais (...) disporem de poderosos meios de imposição de sua legitimidade é que possibilita que ela seja amplamente reconhecida" (LAHIRE, Bernard. A cultura dos individuos. Porto Alegre: Artmed, 2006, p. 39).

${ }^{27}$ Todas as citaçóes literais dos depoimentos de Ismael, que estão no corpo do texto, aparecerão entre aspas.

${ }^{28}$ Claudemir Madeira, referindo-se a essa localidade, afirma que no período da Primeira República, devido à ausência de escolas, os educadores eram solicitados a residirem na casa das famílias, a fim de instruir as crianças da regiāo (MADEIRA, Claudemir Pereira. Da multisseriação à nucleação: a escola municipal Alfredo Dias de Cerrito/RS - Décadas de 1980 a 1990, op. cit.
} 
De acordo com Ismael, as aulas de Maria José eram realizadas em uma casa antiga; entre os materiais utilizados no período de alfabetizaçáo, recorda-se de caneta com tinteiro, de pedra de ardósia para as atividades de matemática, do caderno e da cartilha da professora. ${ }^{29}$ Os métodos de ensino são rememorados sem muita riqueza de detalhes. Ismael enfatiza os ensinamentos de matemática que recebeu, pois tanto ele quanto a professora gostavam muito desse conteúdo. Ainda, conclui que não aprendeu a escrever, mas sim a copiar textos: "cópia sempre tinha, mas ela [professora] nunca fazia ditado, a gente não aprendia a escrever, era só cópia." Interessante observar a distinção que estabelece entre os atos cognitivos de escrever e copiar, ao basear-se em seus parâmetros atuais de domínio da escrita. Entretanto, valoriza, sobremaneira, as aprendizagens que adquiriu com a professora Maria José: "Eu aprendi com ela a ler, escrever e fazer as quatro operaçóes, e naquele tempo lendo e fazendo as quatro operaçôes se defendia muito bem." O uso do verbo defender indica para o sentido prático e, ao mesmo tempo, simbólico, do domínio da leitura e da escrita. Na compreensão de Ismael, saber ler e escrever "defendia" o cidadão da ignorância e da incapacidade, possibilitando a aquisição de novos conhecimentos ou mesmo o acesso a determinadas práticas sociais, a exemplo do que por ele foi evidenciado: "Basta ver que quinze anos depois eu fui pro quartel e com aquilo [aquilo que aprendeu durante um ano] deu pra fazer o curso de cabo, e ser promovido."

Depois de ser alfabetizado, Ismael ganhou dois livros, um de História e outro de Geografia, para que pudesse de forma autodidata adquirir novos conhecimentos. ${ }^{30}$ De acordo com sua narrativa, a professora Maria José indicou ao seu pai a compra de um livro de História do Brasil, que serviria para que ele e suas irmãs tivessem um conhecimento básico sobre a história do país. A obra teria sido adquirida na cidade de Pelotas, o centro urbano mais próximo de sua casa. Outro livro, de Geografia, foi dado por um primo da família materna que, por ser mais velho, já havia utilizado esse material em seus estudos. Ambos os volumes são usados por Ismael ainda hoje, sendo as leituras neles realizadas bastante mencionadas nos depoimentos. ${ }^{31}$

Além desses compêndios, embora afirme que não havia materiais escritos na casa dos pais, Ismael se refere vagamente à existência de almanaques, ${ }^{32}$ e também de um livro que

\footnotetext{
${ }^{29}$ Frade e Galváo (2016), ao analisar os usos de instrumentos e suportes de escrita por pessoas comuns em processo de escolarização na primeira metade do século XX, em Minas Gerais, indicam práticas semelhantes as que são narradas por Ismael (FRADE, Isabel Cristina Alves da Silva; GALVÃO, Ana Maria de Oliveira. Instrumentos e suportes de escrita no processo de escolarização: entre os usos prescritos e os não convencionais (Minas Gerais, primeira metade do século XX). Revista Brasileira de História da Educação, v. 16, n. 1 (40), p. 297-334, 2016).

${ }^{30}$ Conforme Bittencourt: "era essencial garantir a difusão do vínculo nação-território, necessitando-se dos estudos de geografia para o conhecimento do espaço físico do 'país' e da História Nacional para legitimar as formas de conquista do continente que é o Brasil” (BITTENCOURT, Circe Maria Fernandes. Livro didático e conhecimento histórico: uma história do saber escolar. Tese (doutorado em história social) — Faculdade de Filosofia, Letras e Ciências Humanas, Universidade de São Paulo, São Paulo, 1993, p. 30.

${ }^{31}$ Trata-se do livro de Affonso Guerreiro Lima, intitulado Noçôes de história do Brasil, e do livro Geografia elementar, de autoria de José Teodoro de Souza Lobo.

${ }^{32}$ Conforme Park, escrever a história da leitura no Brasil requer o olhar atento para os almanaques: "esses pequenos e despretensiosos livrinhos que moldaram comportamentos e que fizeram/fazem parte da vida de
} 
abordava inovaçóes tecnológicas: "Eu lembro de um livro que tinha tudo isso, a luz elétrica, o apara raio, o avião, tudo isso tinha nesse livro, eu não sei que fim levou esse livro.” Esses relatos nos permitem considerar que, além dos dois livros didáticos, havia outros materiais escritos que circulavam na casa de seus pais.

O primo que lhe deu o livro de Geografia, sobre o qual se refere por várias vezes durante as entrevistas, cursou o primário em uma escola que havia na sede do município de Cerrito, pois morava em um local que lhe possibilitava acesso a essa instituição. Mais tarde, foi trabalhar na zona urbana de Pelotas. A convivência com o primo escolarizado lhe possibilitou algumas aprendizagens, como conta: "Ele ia lá pra casa e era adiantado e queria ensinar, frações decimais foi ele quem me ensinou." Além de frações decimais, no livro de Geografia há uma frase escrita com caneta tinteiro que teria sido feita pelo primo:

\section{Figura 1: Livro didático de Geografia (acervo Ismael)}

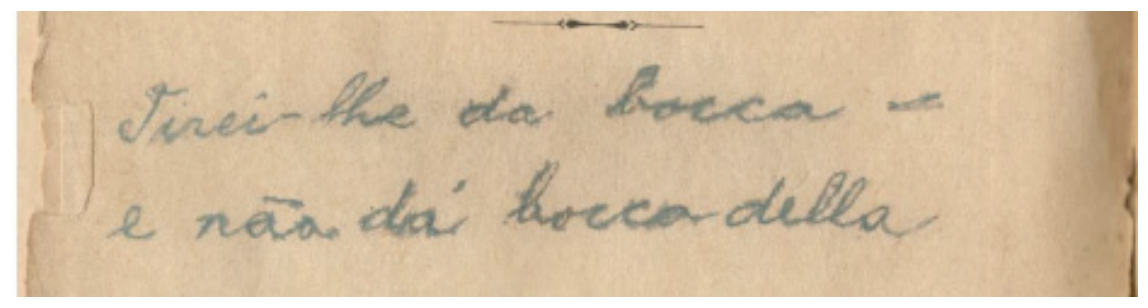

Ismael refere-se ao episódio que resultou nessa escrita do seguinte modo: "Isso aqui é importante, um primo meu que queria me ensinar. Eu disse de uma gata: 'Tirei da boca dela.' E ele escreveu aqui [livro de Geografia] 'tirei-lhe da bocca e não da bocca della'.' Interessante perceber como um acontecimento cotidiano, em que Ismael tirou um objeto da boca de uma gata, serviu-lhe para conhecer um aspecto da norma padrão da língua portuguesa. Outras aprendizagens ocorreram em situaçóes semelhantes, a exemplo do que é por ele narrado:

Eu tinha uns dezesseis anos e eu vim vender lâ, tinha uma barraca aqui em Pedro Osório, filial da de Pelotas, e eu vi o rapaz: pesou a lã com 140 quilos (eu nunca esqueço), e depois foi fazer a conta, colocou 140 quilos e multiplicou pelo preço, pelo valor da arroba. E eu olhando! O que é que ele vai fazer! [Risos.] Cento e quarenta multiplicou pelo valor da arroba e o resultado dividiu por quinze. E eu fiquei pensando... e aprendi! Mas eu não sabia o nome, mas vi como se fazia com qualquer número. Depois era a regra de três simples, que eu ouvia falar muito, mas no fim eu sabia fazer e não sabia o nome. (...) e aprendi, aprendi a regra de três com o barraqueiro! ${ }^{33}$

várias geraçôes" (PARK, Margareth Brandini. Histórias e leituras de almanaques no Brasil. Campinas, SP: Mercado das Letras, 1999, p. 205).

${ }^{33}$ Conforme entrevista realizada em 2010. 
Aprender "regra de três" a partir de uma situação-problema, e posteriormente tomar conhecimento da denominação desse cálculo nos estudos de aritmética, inverte o processo de aprendizagem próprio da cultura escolar, e indica uma aprendizagem baseada na experiência, na prática, que remete a uma lógica própria das culturas orais. ${ }^{34}$ Além da situação narrada, Ismael refere-se a outras atividades, vivenciadas no meio rural, que lhe possibilitavam aprendizagens baseadas na experiência, a exemplo das mediçóes de áreas rurais, que sempre que tinha oportunidade realizava ao lado de agrimensores. Nas culturas baseadas na oralidade o conhecimento é referenciado na experiência humana. ${ }^{35}$ Nesse contexto, os ofícios se adquirem a partir da observação, da prática e com um mínimo de explicação verbal.

Entretanto, em sua trajetória, a convocação para prestar serviço militar certamente foi o momento de maior aprendizagem e, ao mesmo tempo, tensão em sua vida: pelo fato de nunca ter saído da casa dos pais; pela distância do quartel para o qual foi designado, a cerca de quatrocentos quilômetros; pela responsabilidade que tinha em prover o sustento da família, visto que o pai tinha 71 anos na ocasião; por se tratar de um período de guerra mundial; pela experiência relatada por um irmão mais velho, que havia servido durante a Revolução de 1930. Diante desse contexto, Ismael tentou se precaver, levando consigo o dinheiro da venda de umas novilhas e seus dois livros didáticos. Os relatos do irmão sobre o serviço militar lhe fizeram pensar que esses livros poderiam ajudar-lhe a fazer um curso de cabo e assim ascender na carreira militar, possibilitando-lhe melhores condiçóes de trabalho no exército, como relata:

O meu irmão dizia que era coisa horrorosa ficar no quartel como soldado raso, e eu fui então... e me acompanhou a minha Geografia velha, que eu ganhei de presente desse meu primo, e aquela História do Brasil, que foi na mala comigo. (...) Mas eu fui com aquela fé, mas levei comigo os livros. ${ }^{36}$

Essa atitude, por si só, demonstra a crença ${ }^{37}$ na cultura escrita, ou seja, Ismael tinha convicção de que o conhecimento advindo dos livros poderia lhe possibilitar um lugar de distinção na hierarquia militar, havendo um sentido social no uso das obras que levou na mala.

Para Ismael, os dois primeiros meses no quartel foram os mais difíceis, e relembrá-los lhe causa emoção:

\footnotetext{
${ }^{34}$ Cf. ONG, Walter Jackson. Oralidade e escrita. Campinas, SP: Papirus, 1998. Contudo, os estudos de Ong precisam ser complexificados, pois operam com a dicotomização entre oralidade e escrita, mas constituem um instrumental analítico interessante quando se busca caracterizar lógicas típicas das culturas orais.

${ }^{35}$ Idem.

${ }^{36}$ Conforme entrevista realizada em 2009.

${ }^{37}$ Bernard Lahire estabelece a distinção entre crença e disposição para agir, uma vez que, por vezes, os indivíduos podem incorporar crenças (normas, modelos, valores, ideais...) sem ter os meios materiais ou disposicionais para concretizá-las (LAHIRE, Bernard. Patrimônios individuais de disposiçôes: para uma sociologia à escala individual. Sociologia, Problemas e Práticas, v. 49, p. 11-42, 2005. p. 18).
} 
Quando cheguei lá, aquela coisa horrorosa, eu só pensava na minha mãe. Parecia que eu não ia mais ver a minha mãe. Eu tive uma depressão coisa horrorosa, a sorte que eu tinha muita amizade. Eu nunca tinha saído de casa, o máximo que tinha ido era Pelotas. E levei dois dias pra chegar em Quaraí, pra todos os efeitos eu tava longe que era coisa muito séria, e tudo gente estranha! $!^{38}$

O período em que prestou serviço militar certamente cumpriu um papel que ultrapassa a própria vivência no quartel, pois, ao reconstruir, produzir e ressignificar a própria trajetória, Ismael o elege como um dos marcos principais que delimitariam sua vida em diferentes fases. Nas narrativas autobiográficas, as divisóes entre os períodos da vida tendem a ser pontuadas por meio de marcos temporais e/ou espaciais, relativos a eventos ou a relaçóes interpessoais, que são referências para a organização da narrativa. ${ }^{39}$ Em outras palavras, podem ser considerados "pontos de viragem", que definem transformaçôes relevantes na vida do sujeito. As experiências vivenciadas no quartel por Ismael são fortemente evidenciadas em seus depoimentos, podendo ser consideradas um dos mais importantes "pontos de viragem" de sua trajetória. As memórias são carregadas de emoção, de tensão, de sentimentos contraditórios em relação ao que foi vivido naquele período, mas sempre evocadas com certa grandeza: é como se essas vivências tivessem lhe proporcionado os principais ensinamentos de sua vida.

Após uma semana no quartel, Ismael foi submetido ao exame de seleção para o curso de cabo, e com quatro meses de serviço militar, foi promovido para essa nova função. A aprovação no exame de seleção ele atribui aos ensinamentos da professora Maria José e aos livros de História e Geografia, embora também afirme não ter utilizado os exemplares em nenhum momento, pois já conhecia o conteúdo e não havia tempo para a leitura no quartel. Os livros teriam lhe servido como uma espécie de suporte de memória, ou mesmo, tendo uma função especialmente representativa nesse processo de seleção e aprovação.

$\mathrm{Na}$ verdade, não foram apenas os ensinamentos de Maria José e os livros que auxiliaram Ismael: ao ser submetido, oficialmente pela primeira vez, a um teste escrito, obteve o auxílio de um colega para ampliar seus conhecimentos sobre a língua portuguesa, como conta:

Eu tava em alas: como é que eu vou escrever? Eu escrevo, mas fazer um ditado... e tinha um rapaz que tinha estado no patronato, tinha tirado escola, era meu vizinho, e começou a me explicar, é assim: tu póe "m" antes de "p", tu póe "m" antes de "b". E ele tava esperando para fazer o exame e me explicando como se escrevia certas palavras, fizemos o exame e eu passei e ele rodou! ${ }^{140}$

\footnotetext{
${ }^{38}$ Conforme entrevista realizada em 2009.

39 Cf.: OLIVEIRA, Marta Kohl; REGO, Teresa Cristina; AQUINO, Julio Groppa. Desenvolvimento psicológico e constituição de subjetividades: ciclos de vida, narrativas autobiográficas e tensóes da contemporaneidade. Pro-Posiçóes, v. 17, n. 2 (50), p. 119-138, 2006, p. 121.

${ }^{40}$ Conforme entrevista realizada em 2009.
} 


\section{O BISNETO DO COMENDADOR: HERANÇA CULTURAL \\ E FORMAÇÃ̃O AUTODIDATA EM UMA TRAJETÓRIA NO SÉCULO XX \\ Lisiane Sias Manke | Ana Maria de Oliveira Galvão}

Dos 200 soldados que fizeram o teste junto com Ismael, somente 78 foram aprovados, os quais iniciaram o curso de cabo e posteriormente foram submetidos a novo exame, tendo sido selecionados apenas 39 para o cargo. O número restrito de soldados que foram promovidos ao posto talvez indique a significativa "facilidade de aprendizagem" de Ismael, que transformou a capacidade de domínio do sistema alfabético em ferramenta para a aquisição de novos conhecimentos, suficientes para o bom desempenho da função que passou a exercer no quartel.

É possível concluir que o serviço militar aproximou Ismael da cultura escrita, contribuindo para que adquirisse novas aprendizagens e percebesse de forma prática o valor social da leitura e da escrita. Ao ser promovido, as condiçôes de trabalho foram alteradas e a remuneração passou de 31 cruzeiros para 392 cruzeiros mensais. Dessa forma, a intenção inicial de Ismael se concretizou, pois esse foi seu objetivo ao colocar os livros na mala: alcançar melhor posição na hierarquia militar, o que mostra que já havia o reconhecimento, a crença no prestígio e nas vantagens que a cultura escrita e os conhecimentos dela decorrentes poderiam lhe oferecer.

Atuando como cabo, Ismael passou a fazer uso da escrita cotidianamente. Entre seus pertences, ele guarda um dos formulários que produziu no quartel. Trata-se de uma folha de papel almaço que tem como título "Relação numérica e nominal dos praças que fizeram serviço de guarda no quartel do dia 11 para 12 do corrente mês". Em uma tabela, que ocupou todo o espaço da página, criou colunas para o preenchimento dos seguintes dados dos soldados: graduação, número, esquadrão, postos e observaçôes. Consta nessa tabela o nome de quinze soldados e seus respectivos dados, além do nome do cabo Ismael. Na escrita do documento, observamos uma caligrafia firme e clara com uma ortografia bastante precisa, que pressupóem habilidade na escrita.

Ismael considera ter tido bom desempenho como cabo, é o que consta também em seu certificado de reservista: "Não sofreu puniçōes. Comportamento bom." Conforme conta, estabeleceu boas relaçóes e teve o reconhecimento de seu superior, o tenente Emir ${ }^{41}$ que inclusive o convidou a fazer o curso de sargento, por distinguir a eficiência do seu trabalho: "E logo eu peguei muita média com ele, ele tinha muita confiança em mim, e via que eu fazia muito empenho; ele via que eu tava sempre com o lápis e qualquer coisa eu tava anotando." Essa frase nos remete para o papel da escrita, para sua importância e seu reconhecimento social, bem como para o uso que fez dela no período em que esteve no quartel.

Ismael náo pode ser caracterizado como um autodidata apenas pelo fato de náo ser escolarizado (mesmo porque as práticas escolares ou o modelo escolar estavam presentes nos ensinamentos da professora Maria José), mas, principalmente, pelas táticas erráticas que usou ao longo de sua trajetória para ampliar seus conhecimentos e acessar os signos neces-

\footnotetext{
${ }^{41}$ A admiração que Ismael tinha por esse tenente, somada à importância atribuída a esse período em sua vida, o levaram a colocar o nome Emir em seu filho primogênito.
} 


\section{O BISNETO DO COMENDADOR: HERANÇA CULTURAL \\ E FORMAÇÃ̃O AUTODIDATA EM UMA TRAJETÓRIA NO SÉCULO XX \\ Lisiane Sias Manke | Ana Maria de Oliveira Galvão}

sários para o domínio do sistema escrito, como a aquisição de livros após a alfabetização, as aprendizagens com um primo escolarizado, o conhecimento adquirido ao vender lá ou acompanhar os agrimensores, ou mesmo na intensa e marcante experiência vivenciada no quartel, que lhe possibilitou o encontro efetivo com o escrito. Portanto, uma alfabetização bem-sucedida não é suficiente para produzir um autodidata, pois de nada adianta ter aprendido a ler se essa capacidade não se tornar o núcleo de um hábito cultural novo. ${ }^{42} \mathrm{O}$ autodidatismo de Ismael está também, e especialmente, em suas práticas intelectuais de hoje, no modo como se apropria cotidianamente da leitura e da escrita, como discutiremos a seguir.

\section{Entre o oral e o escrito: apropriaçóes e usos da leitura e da escrita}

Ismael casou-se em 1951 com Albertina da Rosa, uma moça oito anos mais jovem que havia conhecido pouco antes de ingressar no serviço militar, em um baile realizado por um clube de futebol rural. Albertina cursou o primário em escola particular vinculada à Igreja Luterana ${ }^{43}$ São João, da localidade de Passo do Santana, onde seus pais moravam. O casal teve quatro filhos, duas mulheres e dois homens, e permaneceu morando na propriedade rural herdada do pai de Ismael até a segunda metade da década de 1990, quando se mudou para a sede do município.

As filhas concluíram o ensino superior e são professoras. Com orgulho Ismael expóe as fotos de formatura delas e dos netos que concluíram cursos superiores, em áreas como Agronomia, Enfermagem, Engenharia Mecânica ou cursos técnicos. Esses elementos indicam a proximidade dos familiares de Ismael com a instituição escolar, o que lhes permite atualmente, estabelecer relaçóes sociais permeadas pelo escrito. A título de exemplo, a constituição do acervo de livros que possui ocorreu especialmente pela mediação familiar.

Mas, que tipo de leitor é esse pai e avô? Que textos lê? Que apropriação faz desses textos? O que escreve e para quê? Enfim, que relação estabelece com a cultura escrita atualmente? Na própria concepção, ele tornou-se um leitor assíduo há aproximadamente vinte anos, quando a leitura e a escrita passaram a fazer parte de suas atividades diárias, uma ocupação do tempo ocioso proporcionado pela aposentaria e pela vida urbana. Contudo, as condiçóes intelectuais para tanto foram sendo adquiridas ao longo de sua trajetória, como se faz perceber na discussão até aqui realizada.

Depois de viver mais de setenta anos no meio rural, com afazeres que lhe ofereciam uma rotina predeterminada, Ismael e a esposa mudaram totalmente a vida cotidiana quando passa-

${ }^{42}$ Como bem expressa HÉBRARD, Jean. O autodidatismo exemplar. Como Valentin Jamerey-Duval aprendeu a ler? In: CHARTIER, Roger (Org.). Práticas de leitura, op. cit., p. 44.

${ }^{43} \mathrm{~A}$ respeito das escolas paroquiais luteranas, existentes em comunidades de imigrantes alemães e pomeranos, consultar: KOLLING, Nilo Bidone. Educação e escolas em contextos de imigração pomerana no sul do Rio Grande do Sul — Brasil. Dissertação (mestrado em Educação) — PPGE/FaE/UFPel, Pelotas, 2000. 


\section{O BISNETO DO COMENDADOR: HERANÇA CULTURAL \\ E FORMAÇÃ̃O AUTODIDATA EM UMA TRAJETÓRIA NO SÉCULO XX}

Lisiane Sias Manke | Ana Maria de Oliveira Galvão

ram a morar na cidade. Nesse novo ambiente, as relaçóes de trabalho são interrompidas e os dias mudam o seu formato, exigindo novas ocupaçóes. $\mathrm{O}$ meio urbano representou uma ruptura na trajetória ${ }^{44}$ de Ismael, acrescida pela situação de viuvez, com a morte de sua esposa logo em seguida. $\mathrm{O}$ momento de ruptura biográfica também favorece que memórias sejam evocadas e vivências revisitadas: "A memória permite a relação do corpo presente com o passado e, ao mesmo tempo, interfere no processo 'atual' das representaçóes." ${ }^{\text {”/5 }}$ Ao remexer no passado, alguns acontecimentos vão ocupando o lugar de mais marcantes e a própria existência vai sendo ressignificada.

Outra situação que deve ser considerada é a de que Ismael passa a ser procurado, após a aposentadoria, por estudantes e/ou pesquisadores da história local, que buscam saber sobre sua origem familiar, promovendo assim, sua aproximação, de forma ainda mais efetiva, com a cultura escrita. A referência à atuação de seus antepassados, especialmente de seu avô paterno, em textos históricos, faz com que seja reconhecido como um possível guardião de memórias. Ao procurá-lo, com vistas à realização de história oral, essas pessoas levaram livros ou cópias de textos/documentos em que há referência ao seu sobrenome; é o que acontece com o texto que indica o avô de Ismael como cirurgião-mor na Guerra do Paraguai. Essas informaçóes sobre a história da família, que até então desconhecia, aguçam seu interesse pela história e consequentemente pela leitura. Por sua vez, as filhas e os netos, percebendo o interesse do pai/avô por tal prática, passam a presenteá-lo com livros, motivando-o a fazer uso da leitura e da escrita.

Assim, Ismael vai constituindo um acervo de livros, textos fotocopiados e outros documentos. Ao analisar o conjunto de livros que possui é possível perceber que se trata de obras, em sua maioria, editadas após os anos de 1980, não sendo, portanto, um acervo antigo. Os livros não são significativos em termos numéricos, sendo o acervo composto por 21 obras e uma enciclopédia. Desses 21 livros, nove são da esfera de circulação ${ }^{46}$ histórica, especialmente sobre história do Rio Grande do Sul e aqueles produzidos por historiadores locais. Nove, por sua vez, são da esfera de circulação didática, entre eles constam dois atlas geográficos, quatro livros didáticos de História e três livros didáticos de Geografia. No acervo, há ainda um dicionário, um livro de técnicas agrícolas e uma Bíblia. A enciclopédia Tesouro da Juventude ${ }^{47}$ é composta por 18 volumes, com ediçãa de 1958.

\footnotetext{
${ }^{44}$ Conforme Lahire, existem circunstâncias em que os patrimônios de disposiçôes são reorganizados, momentos em que há modificaçôes na rotina que levam a pequenas crises individuais ou rupturas biográficas (LAHIRE, Bernard. Retratos sociológicos. Porto Alegre: Artmed, 2004, p. 35).

${ }^{45}$ BOSI, Ecléa. Memória e sociedade: lembranças de velhos. São Paulo: Tao, 1979, p. 9.

${ }^{46}$ A classificação em esferas de circulação social considera que os gêneros textuais se caracterizam mais pelas funçôes comunicativas, cognitivas e institucionais do que pelas suas peculiaridades linguísticas e estruturais (Cf. MARCUSCHI, Luiz Antônio. Gêneros textuais: definição e funcionalidade. In: DIONISIO, Angela Paiva; MACHADO, Anna Raquel Machado; BEZERRA, Maria Auxiliadora. Gêneros textuais e ensino. Rio de Janeiro: Lucerna, 2002, p. 29).

${ }^{47}$ A enciclopédia Tesouro da Juventude é uma coleção de dezoito volumes que reúne conhecimentos de diversas áreas, sendo uma das obras mais populares nesse formato no início do século XX, no Brasil (Cf. DIAS, Kelly Keiko Koti. Estampas coloridas: ilustraçóes na Enciclopédia Tesouro da Juventude, ediçóes de 193(?) e 1957. Anais do XXI Encontro Estadual de História — ANPUH-SP, 2012.
} 


\section{O BISNETO DO COMENDADOR: HERANÇA CULTURAL \\ E FORMAÇÃ̃O AUTODIDATA EM UMA TRAJETÓRIA NO SÉCULO XX}

Lisiane Sias Manke | Ana Maria de Oliveira Galvão

A forma como foi constituindo seu acervo, não apenas de livros, mas também de fotocópias, demonstra a rede de contatos que estabelece com amigos e familiares. Todos os livros que possui lhe foram presenteados; em boa parte deles é possível encontrar a dedicatória de filhas, netos, primas e amigos, a exemplo do que consta escrito em um dos exemplares: "Ao vô Caldeira, preservador das raízes passadas... Uma lembrança com estima, carinho e apreço. Dos netos AMG e MCG. 06/02/04." Os presentes que recebe expressam o que simbolicamente representa para as pessoas com quem convive, ${ }^{48} \mathrm{e}$ isso pode ser percebido ao se observar as temáticas das obras que ganha, em sua maioria vinculadas à História. Quando questionado sobre o fato de náo comprar os próprios livros, ou mesmo visitar a biblioteca que há próxima a sua casa, ele responde: "Não, não, eu sou um velho quase analfabeto!" Essa autorrepresentação se difere, substancialmente, daquela referida em seu discurso, como já analisamos em outro momento deste artigo, quando afirma que "se defendia muito bem" com a leitura, a escrita e as quatro operaçôes nos anos 1930. Certamente os papéis simbólicos atribuídos à escolarização e ao escrito e os usos que deles foram sendo demandados ao longo dessas dezenas de décadas sofreram substanciais transformaçôes, fazendo com que, nos dias atuais, sua origem rural, sua idade e sua condição de cidadáo pouco escolarizado contribuam para que náo se sinta à vontade em frequentar certos espaços, próprios da cultura letrada, como a biblioteca. Assim, percebemos, de forma exemplar, que o letramento somente pode ser compreendido em seu contexto histórico: mesmo que hoje a leitura e a escrita estejam muito mais presentes em sua vida do que naquele momento, os lugares a elas conferidos em suas representaçóes somente podem ser compreendidos em relação àqueles que vão assumindo, de modo mais geral, nos diferentes tempos e espaços sociais vividos. ${ }^{49}$

Em relação às suas práticas de leitura, um aspecto evidencia-se de imediato: Ismael lê, preferencialmente, textos históricos — locais e regionais - e geográficos. Seus principais interesses de leitura centram-se em textos que contribuem para que compreenda a história familiar e a história da localidade em que vive. Por diversas vezes, localizou, durante suas falas, textos que mostram a oposição da família ao partido de Borges de Medeiros, ${ }^{50} \mathrm{e}$ as consequências da posição política assumida: "Eu fui ver naquele livro da História do Rio Grande do Sul a história do coronelismo, (...) e tá ali a história dos municípios (...) Tá o nome do meu avô, o que sofreu e o irmão, roubaram e botaram fogo nas casas, maior horror!” Em

\footnotetext{
${ }^{48}$ Cf. GALVÃO, Ana Maria de Oliveira; OlIVEIRA, Poliana J. P. de. Objetos e práticas de leitura de um "novo letrado": estudo de um percurso individual no século XX. In: GALVÃO, Ana Maria de Oliveira et al. História da cultura escrita: séculos XIX e XX. Belo Horizonte: Autêntica, 2007.

${ }^{49} \mathrm{Se}$, naquele momento histórico, cerca de metade da população adulta do Rio Grande do Sul não sabia ler, hoje esse índice não chega a $5 \%$, o que provoca efeitos inelutáveis na produção de discursos sobre o indivíduo (não) escolarizado (IBGE: Censo, 2010).

${ }^{50}$ Borges de Medeiros era o principal líder do Partido Republicano Riograndense (PRR), tendo sido presidente do estado Rio Grande do Sul entre os anos de 1898 a 1907 e de 1912 a 1927, sendo assim, por cinco mandatos, embora não sucessivos.
} 


\section{O BISNETO DO COMENDADOR: HERANÇA CULTURAL \\ E FORMAÇÃ̃O AUTODIDATA EM UMA TRAJETÓRIA NO SÉCULO XX \\ Lisiane Sias Manke | Ana Maria de Oliveira Galvão}

suas leituras, a história vivida/ouvida e o registro histórico são ressignificados e novamente verbalizados, produzindo conteúdo para suas narrativas sobre o passado.

Nesse mesmo sentido, outro exemplo que contribui para que se compreenda a relaçáo que estabelece com a leitura pode ser observado quando diz:

Eu me criei com meu pai sendo dos federalistas, e quando Getúlio Vargas entrou, eles estavam sofrendo muita perseguição. Então meu pai sempre contava que veio conhecer democracia quando Getúlio foi o governo, porque terminou com aquela bagunça de revoluçóes. Eu com quatro anos eu me lembro da última revolta que houve. (...) Então acabou a bagunça, pra isso eu tenho um livro ai que explica como foi. ${ }^{51}$

É possível concluir que tais experiências familiares fazem com que Ismael posicione-se sempre favorável ao governo Vargas, buscando confirmar suas "experiências pessoais" nos textos que lê. Suas palavras são carregadas de detalhes sobre esse período, como são as histórias vividas e sentidas. A idade que tinha quando Vargas assumiu e concluiu o mandato, o local em que estava e o que fazia no momento das eleiçôes são fatos pessoais que foram vinculados à história nacional, e de igual forma atrelados aos sentidos atribuídos ao texto escrito.

As práticas intelectuais de Ismael, desenvolvidas/aprendidas em diferentes espaços de socialização, parecem, assim, estar ancoradas, especialmente, em experiências que advêm de sua relação com a cultural oral, o que tem implicação na apropriaçáo que faz das leituras que realiza. Ao buscar, por exemplo, legitimar, por meio do escrito, acontecimentos vividos/ouvidos, produz sentidos que, independentemente da discussão desenvolvida no texto, tendem a reforçar posicionamentos decorrentes de suas experiências de vida: "Eu tirei aqui um xérox da República Velha que foi um governo horroroso, eu sei por que me criei escutando o meu pai contar, o banditismo, o roubo." Essa frase, como outras tantas repetidas em seus relatos, aponta para um conhecimento adquirido no ouvir/viver que é confirmado/reforçado pela escrita, ganhando estatuto de verdade: "Eu sou muito de documento, por que documento é o caso escrito." Assim, estabelece uma concepção ambígua sobre a importância do oral e do escrito, pois enquanto a experiência e o oral são valorizados pelo peso do testemunho, "eu sei por que me criei vendolouvindo", o escrito possui maior legitimidade pelo lugar social que ocupa na sociedade grafocêntrica contemporânea: "Então, aqui tá o documento, por que conversa eu digo é conversa de bêbado em boteco, eu gosto é de documento" (grifo nosso).

A busca pela leitura de fatos pontuais, que dialoguem com suas experiências sócio-históricas, faz com que tenha, por vezes, uma prática de "leitura intensiva". ${ }^{22}$ Os livros didáticos de sua preferência, que apresentam de forma mais sintética temáticas do seu interesse, são revisitados por diversas vezes pois, ao ler, estabelece relaçóes, copia, compara e memoriza. Assim, reto-

\footnotetext{
${ }^{51}$ Conforme entrevista realizada em 2009.

${ }^{52}$ No sentido desenvolvido em CHARTIER, Roger (Org.). Práticas de leitura, op. cit.
} 
mar leituras já realizadas torna-se uma prática recorrente, especialmente se tratando dos livros didáticos. Outra característica que decorre desse modo de ler é a leitura fragmentada: seleciona fatos, partes do texto que lhe interessa, realizando uma leitura que condiz com a estrutura textual do livro didático, por apresentar textos isolados que propiciam uma leitura parcial da obra.

Esse parece ser um fato recorrente na relação que Ismael estabelece com os livros: por várias vezes ele usa o termo "me encontrei com", ao se referir a determinado texto localizado sobre o qual teve especial interesse. Em outra oportunidade, ao se referir ao presidente Médici, afirma: "Médici era filho de Bagé, era tenente quando o meu irmão serviu em Bagé. Fizeram a revolução de 1930, e muito cavalo o meu irmão selou pra ele (...). E veja só, eu fui me encontrar com ele [risos], me encontrei com ele no livro!" Nessa lógica, a leitura proporcionaria o encontro com o vivido, com o conhecimento da prática, com as sociabilidades. Por fim, o "encontro", por meio da leitura, com determinado assunto, possibilita a tessitura de novas narrativas orais, pois o acontecimento/ fato histórico passa a ser socializado com evidências trazidas pelo texto lido. Constata-se, assim, em suas práticas de leitura, o trânsito entre o oral, o escrito e as sociabilidades.

\section{Considerações finais}

A análise da trajetória de Ismael permite compreender o modo pelo qual indivíduos que não tinham acesso à instituição escolar, ao longo da história brasileira, promoviam sua entrada no mundo escrito. Além disso, revela os meios pelos quais cotidianamente esses sujeitos ampliavam os conhecimentos advindos da aprendizagem inicial da leitura e da escrita. Coloca, ainda, em evidência, a singularidade da "transmissão do patrimônio imaterial", pois a "herança cultural" pode sofrer transformaçóes a partir do lugar de quem a recebe, ou mesmo, pode não ser incorporada. ${ }^{53}$ Alguns antepassados de Ismael parecem ter tido significativa circulação no mundo da cultura escrita, durante o século XIX. A geração de seu pai, por sua vez, demarca um processo de ruptura ou distanciamento desse universo. A virada do século estabeleceu um contexto de instabilidade política e social e de diluição de heranças materiais advindas da coroa portuguesa. Soma-se, a essa nova situação, a dificuldade de acesso, pela família, a bens culturais, como a escola. O estudo mostra, nesse sentido, que nem sempre o processo de aproximação da cultura escrita nas diferentes gerações de uma mesma família obedece a uma lógica linear. Ismael, vinculado ao mundo rural, neto e bisneto de uma família com significativo status social e cultural na região, não parece caracterizar-se como um herdeiro cultural. Sua trajetória é marcada pela ausência da escola formal e, ao mesmo tempo, pela "crença” na cultura escrita.

Ismael foi construindo sua participação no universo escrito ao longo de sua vida, de forma autodidata, por meio de aprendizagens baseadas na experiência prática, vivenciadas em diferentes momentos e instâncias de socialização. A análise das práticas de leitura e escrita que de-

\footnotetext{
${ }^{53}$ Conforme observa LAHIRE, Bernard. Homem plural: os determinantes da ação, op. cit., p.175.
} 
senvolve atualmente reforça a necessidade de não considerarmos oralidade e escrita como polos dicotômicos, pois mostram a circularidade existente nesses dois modos de expressão, que coexistem e significam-se mutuamente: o oral e o escrito agem simultaneamente na formação das disposiçôes sociais, resultando em usos específicos da escrita e da leitura. Quando afirma: "Eu me criei ouvindo meu pai falar e depois fui me encontrar com o livro", evidencia uma relação em que a oralidade torna-se propulsora da relação estabelecida com o escrito. A leitura lhe proporciona o "encontro" com o conhecimento organizado pela lógica da sociedade grafocêntrica, mas, especialmente, o "encontro" com determinado saber adquirido na experiência e/ou na narrativa oral. A leitura que Ismael realiza caracteriza-se, assim, também por uma apropriaçáo ético-prática, ${ }^{54}$ ou seja, o conteúdo é sobreposto ao estilo e o texto é ancorado não na realidade textual, mas em uma configuração prática. Desse modo, os sentidos que produz ao ler estão fundamentados no conteúdo/tema textual e embasados em suas disposiçôes sócio-históricas.

\section{Fontes}

Arquivo particular de Ismael (diversos documentos pessoais citados no texto).

Inventário registrado na comarca de Piratini (RS), no ano de 1848 (arquivo particular de Ismael).

Jornal Diário Popular — Pelotas (RS), setembro de 1985. (Disponível na biblioteca pública de Pelotas).

Revista do primeiro centenário de Pelotas, obra de João Simôes Lopes Neto, na ediçấo de no 4, de janeiro de 1912.

Entrevista - 14/6/2008

Entrevista - 1/8/2008

Entrevista - 25/8/2009

Entrevista - 7/8/2010

Entrevista - 21/12/2015

Entrevista - 28/3/2016

Entrevista - 2/4/2016

\footnotetext{
${ }^{54}$ Ibidem, p. 92.
} 


\section{O BISNETO DO COMENDADOR: HERANÇA CULTURAL \\ E FORMAÇÃO AUTODIDATA EM UMA TRAJETÓRIA NO SÉCULO XX \\ Lisiane Sias Manke | Ana Maria de Oliveira Galvão}

\section{Referências bibliográficas}

ALBERTI, Verena. Manual de história oral. Rio de Janeiro: Editora da Fundação Getulio Vargas, 2004.

ALCÀZAR I GARRIDO, Joan del. As fontes orais na pesquisa histórica: uma contribuição ao debate. Revista Brasileira de História, São Paulo, v. 13, n. 25/26, p. 40, set. 1992/ago. 1993. AMADO, Janaína; FERREIRA, Marieta (Org.). Usos e abusos da história oral. Rio de Janeiro: Editora da Fundaçáo Getulio Vargas, 1996.

BENSA, Alban. Da micro-história a uma antropologia crítica. In: REVEL, Jacques (Org.). Jogos de escalas. Rio de Janeiro: Fundação Getulio Vargas, 1998.

BITTENCOURT, Circe Maria Fernandes. Livro didático e conhecimento histórico: uma história do saber escolar. Tese (doutorado em história social) — Faculdade de Filosofia, Letras e Ciências Humanas, Universidade de São Paulo, São Paulo, 1993.

BOSI, Ecléa. Memória e sociedade: lembranças de velhos. São Paulo: Tao, 1979.

BOURDIEU, Pierre; PASSERON, Jean-Claude. Les héritiers. Paris: Minuit, 1996.

CARRION, Raul K. M. Os lanceiros negros na Guerra dos Farrapos. Ciências e Letras, Faculdade Porto-Alegrense de Educação, v. 37, 2005.

CHARTIER, Roger (Org.). Práticas de leitura. São Paulo: Estação Liberdade, 2001.

DARNTON, Robert. O beijo de Lamourette: mídia, cultura e revolução. São Paulo: Companhia das Letras, 1995.

. A leitura rousseauista e um leitor "comum" do século XVIII. In: CHARTIER, Roger (Org.). Práticas de leitura. São Paulo: Estação Liberdade, 2001.

DE CERTEAU, Michel. A invenção do cotidiano. Petrópolis, RJ: Vozes, 1994.

DE SINGLY, François. Savoir hériter: la transmission Du goût de la lecture chez lês étudiants. In: FRAISSE, Emmanuel (Org.). Les étudiants et la lecture. Paris: PUF, 1993.

. L'appropriation de L'heritage culturel! Lien Social et Politiques, v. 35, p. 153-165, 1996.

DIAS, Kelly Keiko Koti. Estampas coloridas: ilustraçôes na Enciclopédia Tesouro da Juventude, ediçôes de 193(?) e 1957. Anais do XXI Encontro Estadual de História — ANPUH-SP, 2012. FERRARO, Alceu Ravanello; KREIDLOW, Daniel. Analfabetismo no Brasil: configuração e gênese das desigualdades regionais. Educação e Realidade, v. 29, n. 2, p. 179-200, 2004.

FRADE, Isabel Cristina Alves da Silva; GALVÃO, Ana Maria de Oliveira. Instrumentos e suportes de escrita no processo de escolarizaçáo: entre os usos prescritos e os não convencionais (Minas Gerais, primeira metade do século XX). Revista Brasileira de História da Educação, v. 16, n. 1 (40), p. 297-334, 2016.

GALVÃO, Ana Maria de Oliveira; BATISTA, Antônio Augusto Gomes. Oralidade e escrita: uma revisão. Cadernos de Pesquisa, v. 36, n. 128, p. 403-432, 2006. 
GALVÃO, Ana Maria de Oliveira et al. História da cultura escrita: séculos XIX e XX. Belo Horizonte: Autêntica, 2007.

GALVÃO, Ana Maria de; OLIVEIRA, Poliana J. P. de. Objetos e práticas de leitura de um "novo letrado": Estudo de um percurso individual no século XX. In: GALVÃO, Ana Maria de Oliveira. História da cultura escrita: séculos XIX e XX. Belo Horizonte: Autêntica, 2007. GINZBURG, Carlo. O queijo e os vermes: o cotidiano e as ideias de um moleiro perseguido pela Inquisiçấo. São Paulo: Companhia das Letras, 1987.

HÉBRARD, Jean. O autodidatismo exemplar. Como Valentin Jamerey-Duval aprendeu a ler? In: CHARTIER, Roger (Org.). Práticas de leitura. São Paulo: Estação Liberdade, 2001. KOLLING, Nilo Bidone. Educação e escolas em contextos de imigração pomerana no sul do Rio Grande do Sul — Brasil. Dissertação (mestrado em Educação) — PPGE/FaE/UFPel, Pelotas, 2000.

KÜHN, Fábio. Breve história do Rio Grande do Sul. Porto Alegre: Leitura XXI, 2002.

LAHIRE, Bernard. Homem plural: os determinantes da ação. Petrópolis, RJ: Vozes, 2002. . Retratos sociológicos. Porto Alegre: Artmed, 2004.

. Patrimônios individuais de disposiçóes: para uma sociologia à escala individual. Sociologia, Problemas e Práticas, v. 49, p. 11-42, 2005.

. A cultura dos indivíduos. Porto Alegre: Artmed, 2006.

LEVI, Giovanni. Sobre a micro-história. In: BURKE, Peter. A escrita da história: novas perspectivas. São Paulo: Unesp, 1992.

MADEIRA, Claudemir Pereira. Da multisseriação à nucleação: a escola municipal Alfredo Dias de Cerrito/RS — Décadas de 1980 a 1990. Dissertação (mestrado) — PPGE/FaE/ UFPel, Pelotas, 2010.

MANKE, Lisiane Sias. História e sociologia das práticas de leitura: a trajetória de seis leitores oriundos do meio rural. Tese (doutorado em educação) — PPGE/FaE, Universidade Federal de Pelotas, Pelotas, 2012.

MARCUSCHI, Luiz Antônio. Gêneros textuais: definição e funcionalidade. In: DIONISIO, Angela Paiva; MACHADO, Anna Raquel Machado; BEZERRA, Maria Auxiliadora. Gêneros textuais e ensino. Rio de Janeiro: Lucerna, 2002.

MEIHY, José Carlos Sebe; HOLANDA, Fabíola. História oral: como fazer, como pensar. São Paulo: Contexto, 2007.

MURAKAWA, Clotilde de Almeida Azevedo. Léxico e gramática no Diccionario da Lingua Portugueza (1813) de António De Morais Silva. São Paulo: Alfa, 2006.

OLIVEIRA, Marta Kohl; REGO, Teresa Cristina; AQUINO, Julio Groppa. Desenvolvimento psicológico e constituição de subjetividades: ciclos de vida, narrativas autobiográficas e tensôes da contemporaneidade. Pro-Posiçôes, v. 17, n. 2 (50), p. 119-138, 2006. 
ONG, Walter Jackson. Oralidade e escrita. Campinas: Papirus, 1998.

PARK, Margareth Brandini. Histórias e leituras de almanaques no Brasil. Campinas: Mercado das Letras, 1999.

PASSERON, Jean-Claude; REVEL, Jacques (Dir.). Penser par cas. Paris: Éditions de l'École des Hautes Études en Sciences Sociales, 2005.

QUADROS, Claudemir de. As brizoletas cobrindo o Rio Grande: A educaçáo pública no Rio Grande do Sul durante o governo de Leonel Brizola (1959-1963). Santa Maria: UFSM, 2002. REVEL, Jacques (Org.). Jogos de escalas. Rio de Janeiro: Fundação Getulio Vargas, 1998. REKZIEGEL, Ana Luiza Setti; AXT, Gunter (Dir.). República Velha (1889-1930). Passo Fundo: Méritos, 2007.

\section{Como citar}

MANKE, Lisiane Sias; GALVÃO, Ana Maria de Oliveira. O bisneto do comendador: herança cultural e formação autodidata em uma trajetória no século XX. Topoi. Revista de História, Rio de Janeiro, v. 19, n. 37, p. 102-124, jan./abr. 2018. Disponível em: <www. revistatopoi.org>. 